\title{
Correction to: Morpho-cultural and pathological variability in Phomopsis vexans causing leaf blight and fruit rot of brinjal in Kashmir
}

\author{
Mudasir Bhat $^{1}$ (D) Ali Anwar ${ }^{1} \cdot$ M. Najeeb Mughal ${ }^{1} \cdot$ Fayaz Mohiddin $^{1} \cdot$ Mi Makhdoomi $^{1} \cdot$ Arif Hussain Bhat $^{1}$. \\ Uzma Fayaz ${ }^{1}$
}

Published online: 8 April 2019

(C) Indian Phytopathological Society 2019

\section{Correction to: Indian Phytopathology https://doi.org/10.1007/s42360-019-00128-7}

Unfortunately, some errors occurred in the article.

Page 2 Results should be read:

Total thirty isolates were obtained from diseased samples of brinjal crop from all the locations i.e. Narkora in Budgam (PV1-PV8); Zazuna in Ganderbal (PV16-PV22); Palpora in Srinagar (PV23-PV27); Chadoora in Budgam (PV9-PV12), Lar (PV13-PV15) in Ganderbal and Tailbal in Srinagar (PV28-PV30).

Page 3 right column 3rd sentence should be read:
Some isolates namely PV8, PV15 and PV18 comprising of $10 \%$ of the total isolates showed more than two guttulae in their $\alpha$-conidia.

Page 8 left column 3rd sentence should be read:

However, significant pathological variability existed based on the different response exhibited by brinjal lines to these isolates.

Publisher's Note Springer Nature remains neutral with regard to jurisdictional claims in published maps and institutional affiliations.

The original article can be found online at https://doi.org/10.1007/ s42360-019-00128-7.

Mudasir Bhat

mudasirpatho@gmail.com

1 Division of Plant Pathology, SKUAST-K, Shalimar,

Srinagar, J\&K 190025, India 